\title{
The role of cultural flagships in the perception and experience of urban areas for tourism and culture. Case study: The Royal Opera House in Covent Garden.
}

\author{
Adrian Guachalla ${ }^{1}$
}

Received: 23/07/2012

\begin{abstract}
${ }^{1}$ Buckinghamshire New University, High Wycombe Campus, Queen Alexandra Road, Buckinghamshire HP11 2JZ, UK; +44(0)1494522141 ext 4339; e-mail: a.guachalla@bucks.ac.uk
\end{abstract}

Supervisor: Prof. Robert Maitland and Dr. Andrew Smith

Institution awarding the Ph. D. Degree: University of Westminster

Date of defence: $6^{\text {th }}$ June 2011

(c) 2013 International University College. All rights reserved

Citation: Guachalla, A. (2013). The role of cultural flagships in the perception and experience of urban areas for tourism and culture. Case study: The Royal Opera House in Covent Garden. Doctoral dissertation summary. European Journal of Tourism Research 6(1), 83-87.

\section{Goal and objectives of the dissertation Goal}

To critically evaluate the role of the Royal Opera House in the perception and experience of cultural tourism in Covent Garden.

\section{Objectives}

These have been expressed as research questions as follows:

$\checkmark$ What does the term 'Covent Garden' represent for the visitor?

$\checkmark$ What motivates tourists to visit Covent Garden?

$\checkmark$ How is a visit to Covent Garden experienced by the visitor?

$\checkmark$ How is Covent Garden perceived by the visitor?

$\checkmark$ How does the Royal Opera House influence the perception and experience of Covent Garden?

DOCTORAL DISSERTATION

\section{Methodology}

A qualitative social constructivist approach was adopted, through which the tourist's mechanisms of interpreting their surroundings and the nature of their cultural experiences in Covent Garden were explored. 306 semistructured interviews were conducted throughout six different locations in the area and inside the flagship building to capture wide ranging data from a contrasting set of domestic, international, first-time and repeat visitors. These were subsequently transcribed and analysed using qualitative data analysis software ( $\mathrm{N}^{*}$ Vivo), leading to an initial set of categories that emerged from the literature review and stemmed from the data itself. These categories were re-read resulting in an extensive list of codes that addressed the tourists' perception and experience of Covent 
The role of cultural flagships in the perception and experience of urban areas for tourism and culture. Case study: The Royal Opera House in Covent Garden. Doctoral dissertation summary.

Garden and how the Royal Opera House effectively influences these processes.

\section{Results}

The evidence analysis revealed that the Royal Opera House does not have a strong influence on many tourists' perception and experience of Covent Garden, which is seen as a place for shopping and relaxation rather than high arts despite the efforts made to provide it with a more attractive architectural front and its policies for social inclusion. However, other visitors perceive the Opera House as a pinnacle of high culture depending on their level of appreciation for opera and ballet regardless of the building's physical appearance. The notion of cultural distance (McKercher and Chow Si-Ming, 2001) exerts an influence in these perceptions as the area's visitors tend to relate their surroundings to what they are familiar and unfamiliar with. The visitors' age also plays an important role in their perception and experience of place as the data collected revealed that the older age groups tend to have a more inquisitive attitude in regards to their tourist experiences, which can also be understood as deeper. This is also notable in the fact that the majority of the interviews conducted inside the House were with visitors that belonged to the older age groups and were mostly local or domestic tourists. On the other hand, younger tourists are more likely to focus their visit on leisure and entertainment. The presence and behavior of other visitors in the area also prove to exert an impact on the tourist's perception and experience of place. They tend to engage in communal activities such as watching street entertainment and provide each other with behavioral cues that manifest themselves in a slower pace of movement and a relaxed attitude when experiencing the precinct. This is also related to the area's built environment and urban characteristics as the streets are pedestrianised, allowing visitors to roam and explore their surroundings freely. Covent Garden can be seen as a multifaceted precinct as the area's different locations vary in terms of size and scale and the range of leisure and cultural opportunities available. The area's Piazza is an open space characterised by the presence of the Market, street entertainment and outdoor eating and drinking facilities that grant it with a continental and cosmopolitan ambience. Other locations such as Seven Dials provide visitors with other types of experiences given the smaller scale of its streets.

The Royal Opera House is perceived as a valuable cultural asset for the country given the high quality of performances and famous performers it attracts as a result. Its name is associated with elitism, exclusivity and monumental architecture. However, the building's physical presence in the area does not provide the same visual stimuli that other standalone flagship developments such as the Sydney Opera House provide for example. Regardless of this, the Covent Garden theatre is a functional space for opera and ballet productions and the quality of its performances are a reflection of this. Therefore, its importance and role in the tourist's perception and experience of place depends on the individual's awareness of the building and personal interest in its cultural products.

\section{Theoretical conclusions}

Flagships developments tend to be stereotyped as grandiose free standing buildings detached from dense urban areas and contemporary research on this topic reflects this. But the understanding of cultural flagships from the visual perspective alone is limited as their functionality and heritage should also be at the core of their discussion. An exclusive focus on monumental design can distract from the main activity of an institution, diluting its role as a flagship provider of culture. The perception and experience of both cultural flagships and urban areas for tourism and culture depend directly on the tourist's individual background as cultural distance, past experiences and age play pivotal roles in the way they perceive and experience objects and places. Tourists themselves are active elements of an area's place making system, and can potentially have a determining effect on other people's perception and experience of place.

\section{Practical application of the dissertation}

The age structure of in-house interviewees suggests that attendance to opera and ballet performances are more popular amongst the 
older age groups. As consistently highlighted by the evidence collected and analysed, a younger generation needs to be nurtured to secure the future of the production of these art forms. Furthermore, the Opera House is heavily subsidised by public funds, which confers it with a social responsibility to make attendance to performances as accessible as possible to a variety of markets. This research has revealed that audience development initiatives can succeed in providing positive experiences to the area's visitors. Therefore, cultural policy should aim to further develop and deliver these initiatives to potential new markets to encourage attendance and awareness of the Opera House in the area. By doing this, the relationship between the flagship and the area would be strengthened, leading to a tighter cohesion between the two and integrating the consumption of high arts at the venue with leisure and commercial experiences available in the area.

\section{Content of the dissertation}

Abstract of chapter one: Introduction

The economic contribution of the theatre industry to the UK's economy is approximately 2 billion GBP per annum (UK Trade and Investment, 2010). This contribution is not only related to cultural consumption, but to income generated through additional expenditure in areas were venues for the performing arts and other commercial activity are clustered. Opera Houses as cultural flagships play an important role as catalysts for tourist and economic activity indicating that there is a strong case for conducting the study as it focuses on an established Opera House located at the core of an area renowned for its leisure opportunities and vibrant commercial sector.

Abstract of chapter two: Cultural Tourism, Cultural Tourists and the Tourist Experience

Smith (2007) proposes that novel forms of cultural tourism provide experientially engaging and active experiences to users. Tourists can have deep or shallow cultural experiences regardless of their level of cultural motivation, tend to be attracted to places and experiences that are both familiar and unfamiliar to them and the nature of these experiences is subject to the individual's personal background
(McKercher and Chow Si-Ming, 2001; McKercher, 2002). Other tourists and their behaviour may also exert an influence as suggested by the notion of co-tourism (Harvey and Lorenzen, 2006) leading tourists to interact and engage in communal activities in what is referred to as 'the tourists' performance' (Edensor, 2001).

Abstract of chapter three: Urban Areas for Tourism and Culture

From the physical perspective, the notion of an urban village focuses on the range of uses and built environment that caters for tourists and the host community. From the clientele perspective, these precincts may have been developed to attract tourists to areas that can be understood as tourist bubbles (Judd and Fainstein, 1999). From the business perspective, they can be seen as entertainment districts given the ample array of opportunities for leisure and consumption. The cultural quarters perspective (Roodhouse, 2006) focuses on cultural activity concentrated within the area and cultural flagships can play a fundamental role in strengthening a precinct's cultural offer and attracting other businesses (Mommaas, 2004). These approaches are not mutually exclusive.

\section{Abstract of chapter four: Cultural Flagships} Cultural flagships are not only architectural artefacts shaping a destination's urban landscape. They also serve as signifiers of cultural and economic prosperity (Wing Tai Wai, 2004) which can be directly linked to a city's image as a destination for tourism and culture as the Sydney Opera House is (Colbert, 2003). It is also important to consider their use and heritage to assess their cultural value (Smyth, 1994). Opera Houses face the challenge of providing passive experiences based on culture that is perceived to be elitist, exclusive and expensive. Therefore, audience development initiatives are needed for cultural flagships to not only be seen as visual assets but to also be valued as working buildings and institutions (Belfiore, 2002).

Abstract of chapter five: Covent Garden and the Royal Opera House 
The role of cultural flagships in the perception and experience of urban areas for tourism and culture. Case study: The Royal Opera House in Covent Garden. Doctoral dissertation summary.

Covent Garden is a popular area for tourism and cultural consumption, with distinctive architecture, heritage and a range of attractions and leisure opportunities which developed organically over time. There is a beneficial association between commerce and performing arts in the area (Richardson, 1995). The Royal Opera House is firmly established at its core and stands as a world renowned provider of culture with rich history of its own. It was subjected to a redevelopment scheme providing the building with a fresh architectural front and added facilities. This raises questions regarding the role that an old cultural flagship made new plays in a tourism precinct's sense of place and draw towards the cultural tourist.

\section{Abstract of chapter six: Methodology, Method and Data Analysis}

Social constructivism was the approach adopted to conduct the study as it allows individuals to develop their views according to their subjective mechanisms of interpretation and unique processes of creating their own realities (Quinn Patton, 2002). Semi-structured interviews were used as data collection tools because they are flexible means of capturing wide ranging data (Finn et al., 2000). The interviews enquired about the tourists' motivation to visit and their perception and experience of Covent Garden and the Royal Opera House. These were subsequently analysed using qualitative data analysis software ( $\mathrm{N}^{*}$ Vivo) and coded reiteratively in two stages (Bryman, 2004). The first stage led to an initial set of categories that was re-read and derived in a list of codes that supported the evidence analysis.

\section{Abstract of chapter seven: Evidence Analysis}

The area attracts younger international tourists and the flagship is visited by on alder domestic segment. Motivations to visit include the area's centrality, typicality, commercial activity, heritage and performing arts. The precinct is experienced by roaming freely throughout its pedestrian streets, and the slower pace of movement of visitors makes them perceive the area as a place for leisure and relaxation. The flagship building does not have a visual impact because of its 'hidden' location in a dense urban area. Its Royal title suggests opulence and grandiosity, but many visitors fail to identify it visually. However, it is seen as a cultural flagship as the UK's leading Opera House and many visitors benefit from effective audience development initiatives.

\section{Abstract of chapter eight: Discussion}

An individual's personal background makes them perceive the area and the flagship from different perspectives, which relates to Kelly's (1995) personal construct theory. They are attracted to the familiar as it provides them with a sense of safety and assurance, and to the unfamiliar as it excites their desire to experience the unknown. Covent Garden's flexibility and plasticity allows tourists to interpret it intrinsically. For some, the Royal Opera House is the heart and soul of the area as a place for performance. For others, it is a subtle architectural artefact amidst the sights and sounds of its vibrant Piazza. But the relationship between the area and the flagship is strong because of its positive input into the visitor's perception of London as a cosmopolitan destination for culture.

\section{Abstract of chapter nine: Conclusions and Recommendations}

Covent Garden's place making system is determined by its built environment, activity based and human based elements, which strongly relates to Franck and Steven's (2007) notion of 'loose spaces'. The area's distinctive architecture and infrastructure caters for a variety of visitors that engage in communal activities influencing each other's experience and perception of place, and motivates them to visit for different reasons. The area and the flagship are interpreted intrinsically in a process of cultural appraisal, where cultural distance and depth of experience play pivotal roles. The high levels of visitation in the area suggest that quantitative studies could be conducted to further understand these topics. But the study is limited as the semi-structured nature of the interviews and heterogenic sample used restricted the ability to compare them.

\section{References:}

Belfiore, E. (2002). Arts as a means of alleviating social exclusion: Does it really work? A critique of instrumental 
cultural policies and social impact studies in the UK. International Journal of Cultural Policy, 8(1), 91-106.

Bryman, A. (2004). Social Research Methods. $\left(2^{\text {nd }}\right.$ ed.) Oxford: Oxford University Press.

Colbert, F. (2003). The Sydney Opera House: An Australian Icon. International Journal of Arts Management, 5(2), 6977.

Edensor, T. (2001). Performing Tourism, Staging Tourism: $(\mathrm{Re})$ producing Tourist Space and Practice. Tourist Studies, 1(1), 59-81.

Finn, M., Elliot-White, M. \& Walton M., (2000). Tourism and Leisure Research Methods: Data Collection, Analysis and Interpretation. Essex: Pearson Education.

Franck, K., \& Stevens, Q. (2007). Loose Space: Possibility and Diversity in Urban Life. London: Routledge.

Harvey, D., \& Lorenzen, J. (2006). Signifying Practices and the Co-tourist. Tourismos, 1(1), 9-27.

Judd, D., \& Fainstein, S. (1999). The Tourist City. London: Yale.

Kelly, G. (1955). The Psychology of Personal Constructs. New York: Norton.

McKercher, B. (2002). Towards a Classification of Cultural Tourists. International Journal of Tourism Research, 4(1), 2938.
McKercher, B., \& So-Ming, B. C. (2001). Cultural Distance and Participation in Cultural Tourism. Pacific Tourism Review, 5(1), 23-32.

Mommaas, H. (2004) Cultural Clusters and the Post-industrial City: Towards the Remapping of Urban Cultural Policy. Urban Studies, 41(3), 507-532.

Patton, M. (2002). Qualitative Research and Evaluation Methods. London: Sage.

Richardson, J. (1995). Covent Garden Past. London: Historical Publications.

Roodhouse, S. (2006). Cultural Quarters: Principles and Practice. Bristol: Intellect.

Smith, M. (2007). Cultural Tourism in a Changing World. Tourism: The Journal for the Tourism Industry, 1(1), 18-19.

Smyth, H. (1994). Marketing the City: The Role of Flagship Developments in Urban Regeneration. London: E\&FN.

UK Trade and Investment (2010). Applause! Applause! More Dramatic Success for London's Theatreland. URL: http://www.ukti.gov.uk/investintheuk/uni tedkingdom/london/item/112906.html (Accessed on 11th December 2010)

Wai, A. W. T. (2004). Place Promotion and Iconography in Shanghai's Xintiandi. Habitat International, 30(2), 245-260. 